\title{
Dexamethasone implantation in birdshot chorioretinopathy - long-term outcome
}

This article was published in the following Dove Press journal: International Medical Case Reports Journal

\section{Asima Bajwa' \\ Travis Peck'}

Ashvini K Reddy ${ }^{2}$

Peter A Netland'

Yevgeniy Shildkrot ${ }^{\prime}$

'Department of Ophthalmology, University of Virginia, Charlottesville, VA, USA; ${ }^{2}$ Johns Hopkins Wilmer Eye Institute, Baltimore, MD, USA
Correspondence: Yevgeniy Shildkrot Department of Ophthalmology, University of Virginia, 1300 Jefferson Park Avenue, Charlottesville, VA 22908, USA Tel + I 4349820046

Fax +I 4342432896

Email ys8q@hscmail.mcc.virginia.edu
Purpose: To evaluate the long-term efficacy of the $0.70 \mathrm{mg}$ dexamethasone (DEX) intravitreal implant in patients with birdshot chorioretinopathy (BSCR).

Methods: Retrospective descriptive case series of BSCR patients treated with DEX implant (DEX implant $0.70 \mathrm{mg}$, DEX). Patients receiving treatment between September 2013 and November 2016 with a minimum follow-up (FU) of 12 months were included. The outcomes of primary interest were vision-related functioning, Snellen visual acuity, ocular inflammation status, presence or absence of vasculitis, change in central macular thickness, and development of glaucoma and/or cataract. Change in vision-related functioning was evaluated by comparing the National Eye Institute Visual Function Questionnaire-25. The outcomes were assessed at baseline, after DEX implant, at time of relapse, and at last FU.

Results: Three patients (six eyes) were included in the study and were followed for 1-3 years. They received 1-4 DEX implants OU. All patients demonstrated improvement in National Eye Institute Visual Function Questionnaire-25 scores. Mean Snellen visual acuity better than or equal to 20/40 was seen in three eyes at baseline and five eyes at last FU. At induction, all of the patients (six eyes) had active vitritis and two (four eyes) had retinal vasculitis. All three patients (six eyes) were quiet at last FU. One patient (two eyes) developed bilateral ocular hypertension requiring topical therapy and discontinuation of DEX implants. Two patients (three eyes) developed posterior subcapsular cataract during therapy. Two patients (four eyes) showed progression of disease while on DEX therapy. All patients were eventually transitioned to systemic immunosuppressive drug therapy.

Conclusion: BSCR patients receiving DEX implant experienced clinically meaningful improvements in patient-reported visual function as well as ocular inflammation. However, patients in this study required repeat implantation and were unable to be maintained on DEX implant long term due to development of adverse effects or progression of disease. Eventually, it was necessary to transition to systemic immunosuppressive therapy in all patients.

Keywords: birdshot chorioretinopathy, dexamethasone implant, inflammation, uveitis

\section{Introduction}

Birdshot chorioretinopathy (BSCR), also identified as birdshot retinochoroiditis, is characteristically seen in Caucasian patients in their sixth decade of life with a strong genetic connotation with the human leukocyte antigen HLA-A29. ${ }^{1}$ It is uncommon and is responsible for $6 \%-8 \%$ of cases of posterior uveitis. The clinical presentation is usually one of a gradual deterioration of vision associated with floaters. ${ }^{2}$ It is characterized by the presence of multiple depigmented ovoid spots in the retinal pigment epithelium and the choroid. ${ }^{3-5}$ The pathophysiology of BSCR remains unknown, but 
evidence suggests an autoimmune etiology, with activated T-cell-mediated immunity directed against retinal $\mathrm{S}$ antigen and other retina-specific proteins. ${ }^{6-8}$

BSCR patients may progress to blindness without treatment, usually due to chronic cystoid macular edema (CME) or diffuse retinal dysfunction. ${ }^{9,10}$ Visual impairment can occur without obvious clinical evidence of active inflammation, and hence these patients often require chronic immunosuppressive drug therapy (IMT) to control their disease. ${ }^{11-13}$ However, unlike many other forms of uveitis (lupus, sarcoid, etc), BSCR has no known extraocular manifestations. Consequently, systemic agents such as mycophenolate mofetil (MM), cyclosporine (CS), and adalimumab do not bring benefit beyond controlling ocular inflammation. Intraocular drug delivery provides a potentially useful alternative as it could decrease the well-documented side effects of systemic immunosuppression. The long-acting fluocinolone acetonide (Retisert; Bausch \& Lomb, Rochester, NY, USA) and dexamethasone (DEX; Allergan, Inc., Irvine, CA, USA) intravitreal implants were approved by the US Food and Drug Administration for noninfectious posterior uveitis. These devices enable long-lasting steroid delivery directly to the posterior segment of the eye ball, while minimizing systemic absorption and, thus, provide a safer adverse event profile.

Several authors have published reports on the utility of the fluocinolone acetonide implant in the management of BSCR. ${ }^{14-16}$ There are no publications in the English literature documenting outcomes $>1$ year after the implantation of the long-acting dexamethasone implant, DEX.

Walsh et al ${ }^{17}$ previously published the initial response to DEX implantation in three patients included in this paper. The purpose of this case series is to report the long-term efficacy of the DEX implant in patients with BSCR.

\section{Methods}

\section{Study design}

This was a retrospective descriptive case series. The database of the Department of Ophthalmology at University of Virginia, Charlottesville, was reviewed, and all BSCR patients who received DEX intravitreal implants from September 2013 through November 2016, with a minimum of 12-month follow-up (FU) were included in the study. DEX implantation was done in cases of newly diagnosed BSCR patients if they elected for this treatment after discussion of risks, benefits, and alternatives. This study was approved by the University of Virginia, School of Medicine's Institutional Review Board and was conducted in accordance with the Declaration of Hel- sinki. A written informed consent was signed by all patients to have their case details and images published.

\section{Efficacy outcomes}

The outcome features of primary interest were vision-related functioning, best-corrected visual acuity (BCVA), ocular inflammation status, presence or absence of vasculitis, and/or CME. Adverse events recorded were development of ocular hypertension (Oc HTN) and cataract. Failure was defined as relapse of ocular inflammation despite repeated DEX implantation, intolerance to significant side effects, or both. Disease progression was defined as vasculitis on fluorescein angiogram (FA) and progression of mean defect (MD) on visual field analysis.

\section{Case reports}

\section{Case 1}

A 55-year-old male sought treatment for HLA A 29-positive BSCR in our uveitis clinic. The patient began therapy with CSA $200 \mathrm{mg} / \mathrm{d}$. At 3-month FU, he had stable vision but persistent vitritis with worsening visual fields. The possibility of adding another immunosuppressive agent or oral corticosteroids was discussed, but he deferred. On his subsequent visit, he presented with worsening vision, persistent vitritis, and disc hyperemia. Humphrey visual field test (HVF) demonstrated progressive field loss involving central fixation (MD -13.5 OD, -14.5 OS). Poor perfusion was seen on FA. A minimal nonvisually significant epiretinal membrane (ERM) OU along with subretinal fluid (SRF) OD was evident on optical coherence tomogram (OCT) (Figure 1A and B).

Given his subjective complaints, desire for treatment, and objective visual decline, the patient was given the alternatives including a second immunosuppressive agent and DEX. The patient elected for DEX OU in addition to completing his prednisone taper. Two months after receiving DEX, his vision improved, inflammation was well controlled, and SRF was resolved on OCT. He subsequently received a second DEX OU 6 months later due to relapsed inflammation. He received three DEX implants each eye, approximately 6 months apart. The patient was lost to FU for 8 months after his third implant, at which time decreased foveal sensitivity as well as the beginning of a posterior subcapsular cataract were noted. He then opted for addition of MM 2,000 mg/d to CS $200 \mathrm{mg} / \mathrm{d}$, to lower risk of cataract progression and need for reimplantation every 6 months. At his last visit, his eyes were quiet with stable vision, resolved CME (central macular thickness 


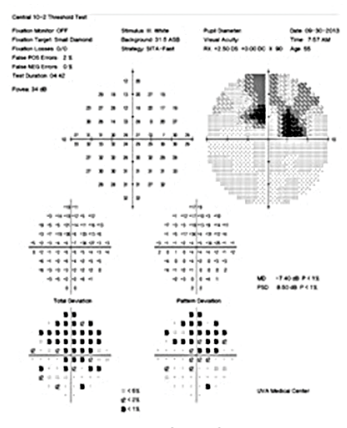

Baseline visual field OD

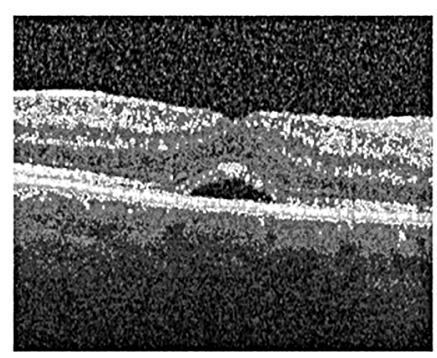

Baseline OCT OD

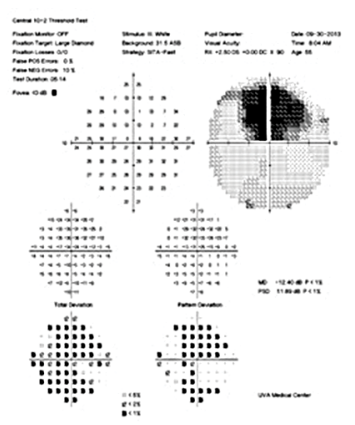

Baseline visual field OS

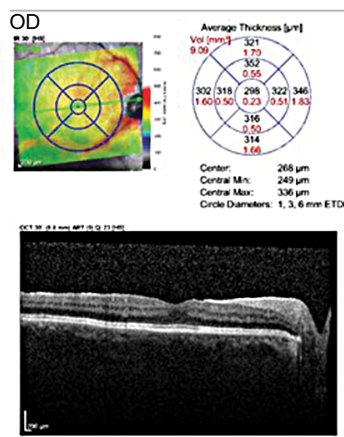

OCT OD relapse

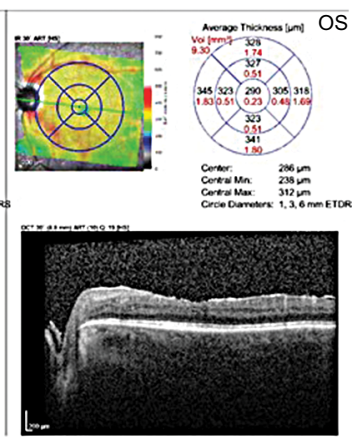

OCT OS relapse

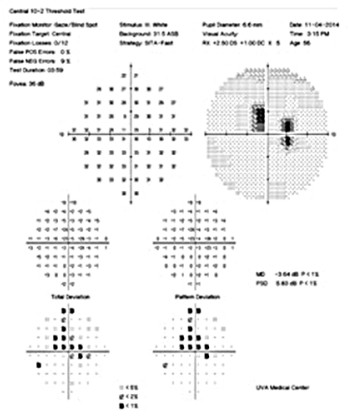

Final visual field $O D$
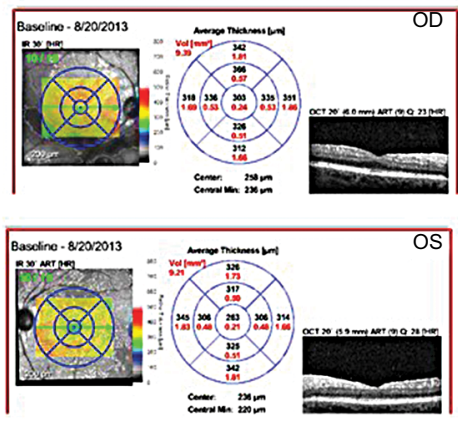

OCT OU final

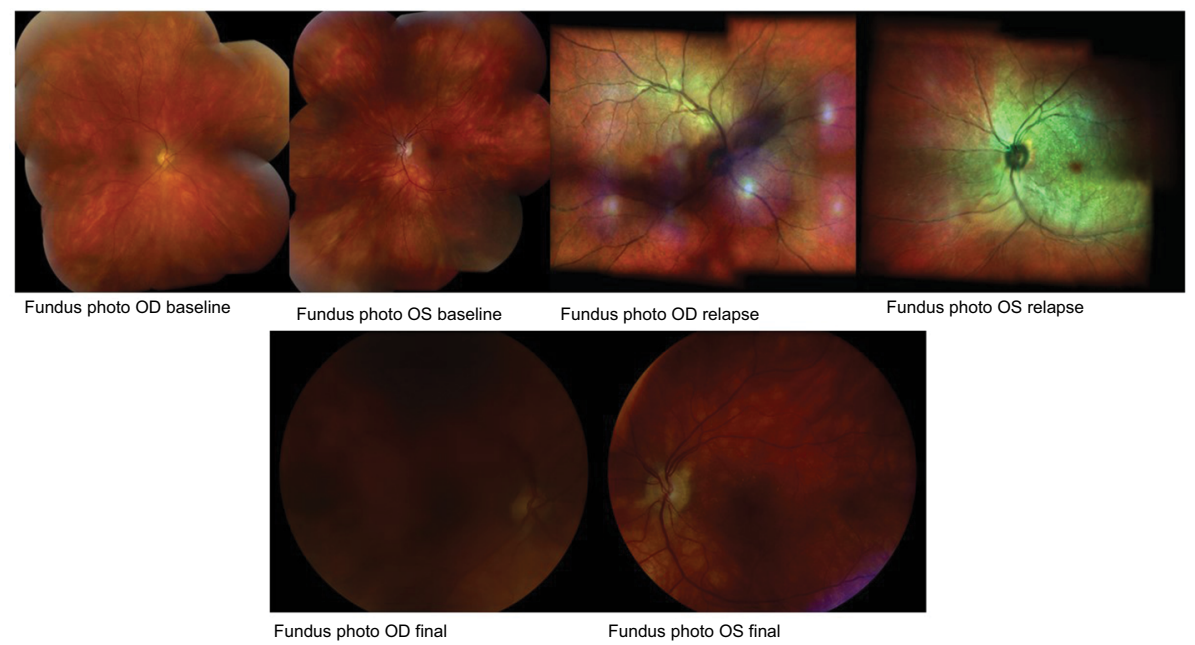

Figure I Case I HVF (baseline and final visit) and macular OCT at baseline, relapse, and final visit; case I fundus photos at baseline, relapse, and final visit. Abbreviations: HVF, Humphrey visual field; OCT, optical coherence tomography.

[CMT] $237 \mathrm{OD}, 227 \mathrm{OS})$, and improved MD on HVF $(-9.35$ OD,-8.47 OS $)$.

The National Eye Institute (NEI) composite visual scores are as follows:

- Baseline: 55.19

- Postimplant: 64.28

- Final FU: 75.12

The National Eye Institute Visual Function Questionnaire-25 (NEI VFQ) score for this patient showed improve- ment after Ozurdex implant and at the end of FU after adding MM to CS.

\section{Case 2}

A 47-year-old male witth HLA A 29 BSCR visited to seek treatment at our uveitis clinic. Ocular and systemic therapies were discussed with the patient. He elected DEX OU and experienced subjective improvement in visual acuity and reduction in inflammation. However, he required a second implant OU at his 6-month FU visit due to relapsed 


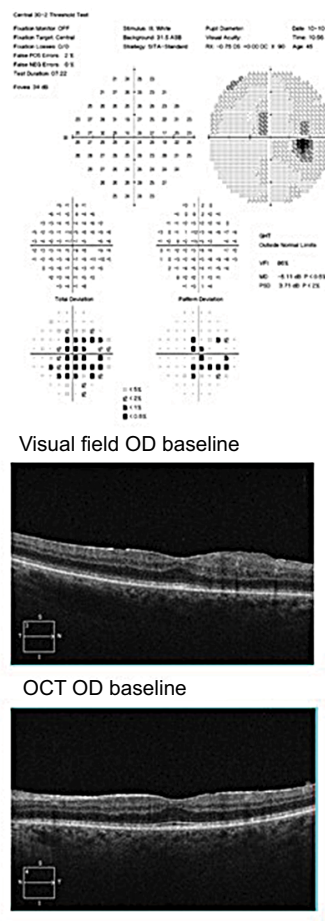

OCT OS baseline

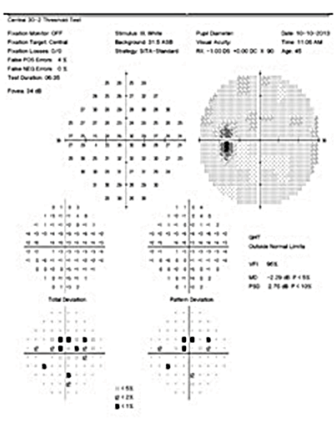

Visual field OS baseline

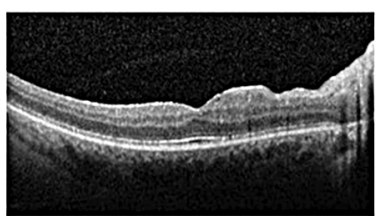

OCT OD Relapse

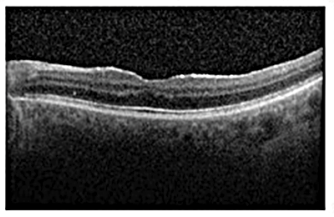

OCT OS relapse

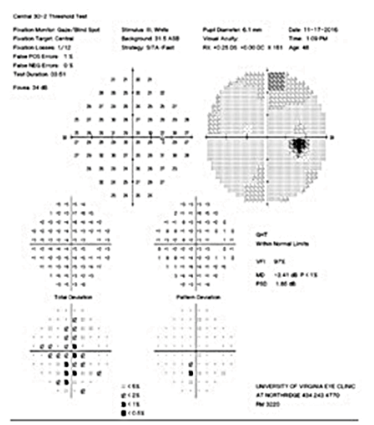

Visual field OD final

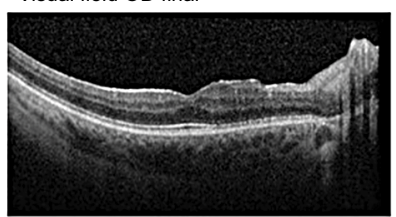

OCT OD final

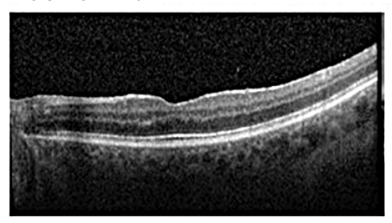

OCT OS final

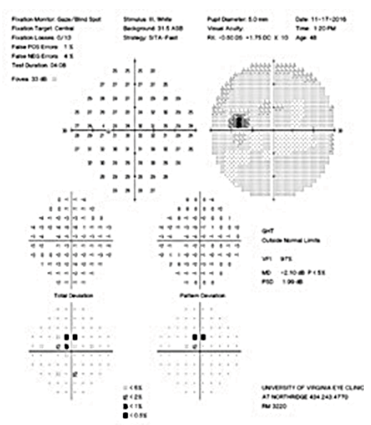

Visual field OS final

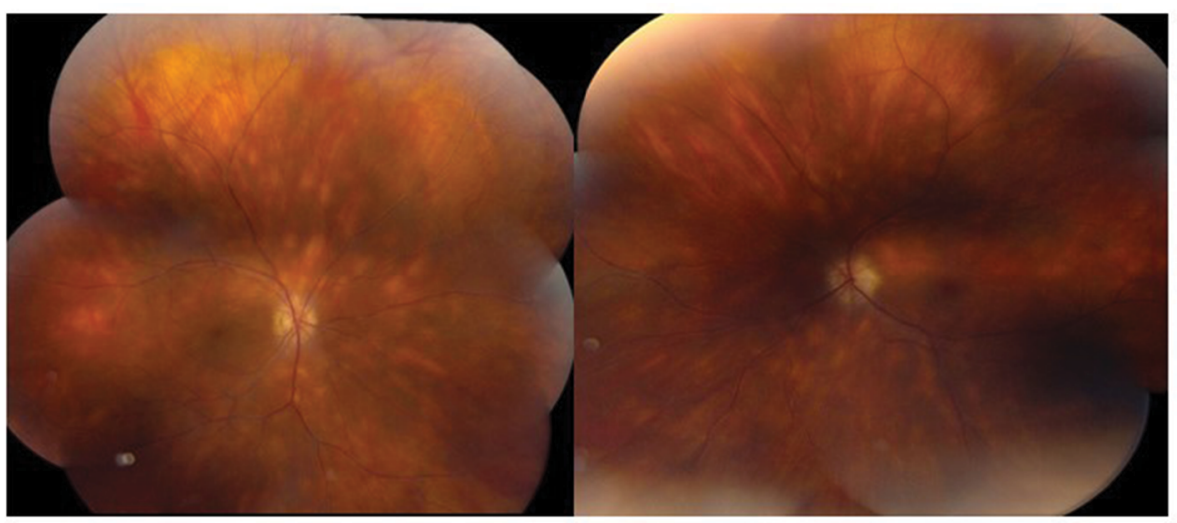

Fundus photo OD baseline

Fundus photo OS baseline

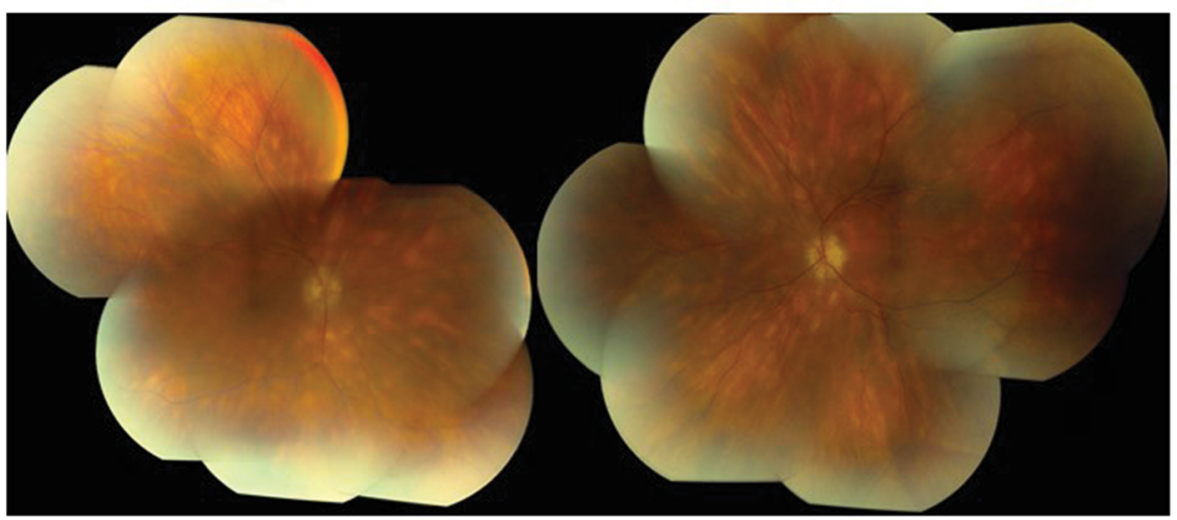

Fundus photo OD relapse

Fundus photo OS relapse

Figure 2 Case 2 HVF and macular OCT at baseline, relapse, and final visit; case 2 fundus photos at baseline visit and relapse.

Abbreviations: HVF, Humphrey visual field; OCT, optical coherence tomography. 
ocular inflammation. At this point, he was started on topical timolol for Oc HTN (IOP 22 OD, 24 OS). At subsequent visits, early posterior subcapsular cataract with epiretinal membrane OU were noted and full-field ERG showed increased latency of 40.12 milliseconds (ms). Over the course of 2 years, he received four DEX implants OU, before switching to oral MM. The patient was satisfied with DEX therapy at the time without significant inflammation. However, enlarged blind spot on HVF (MD OD -6.5 , OS -4.8), leakage on FA, and increased implicit time (44.48 $\mathrm{ms})$ with decreased $\mathrm{b}$ wave amplitude $(50 \mathrm{mV})$ on ERG indicated that the disease was continuing to progress despite repeated DEX injections. Additionally, posterior subcapsular cataract formation and Oc HTN were noted OU. At last FU, patient had quiet eyes with stable vision and IOP. HVF showed improved MD as well (MD OD -4.2, OS -3.0) (Figure 2A and B).

Composite NEI VFQ scores are as follows:

- Baseline: 75.34

- Postimplant: 93.56

- Final FU: 85.41

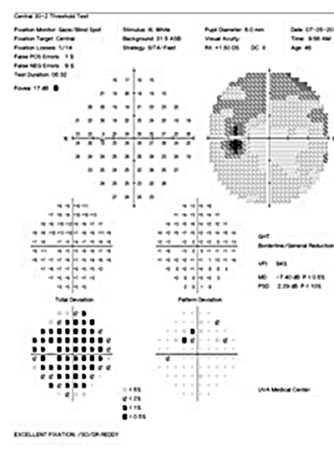

Visual field OS baseline

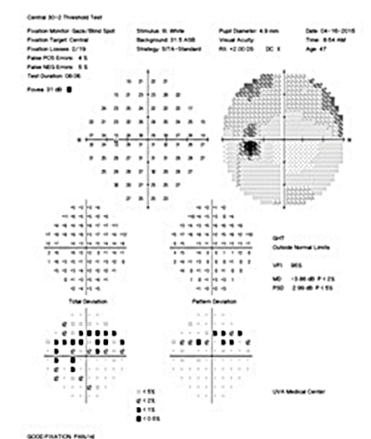

Visual field OS relapse

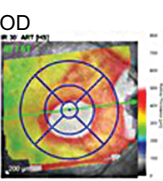

\section{Case 3}

A 46-year-old HLA A 29 male was diagnosed with BSCR and uveitic glaucoma. The patient was counseled on potential treatments including systemic therapy and side effects of both ocular implant and oral medication. He opted for DEX OU, after which he continued on his antiglaucoma medication (Cosopt) as well. At his 1-month FU visit after DEX implant, IOP spiked to $45 \mathrm{OD}, 54 \mathrm{OS}$, although CMT was reduced to 347 OD, 297 OS with improved BCVA. Brimonidine and latanoprost were added to Cosopt OU. Later, he relapsed with CMT of 541 OD, 353 OS with sustained increased IOP. The patient was started on MM. At 6 months into IMT treatment, he was able to discontinue antiglaucoma medications. Visual deterioration (20/30 OD, 20/40 OS) was deemed likely due to persistent macular edema (CMT 450 OD, 350 OS) and subfoveolar fluid (Figure 3), so referral was made to rheumatology to start additional or alternative systemic IMT. He was
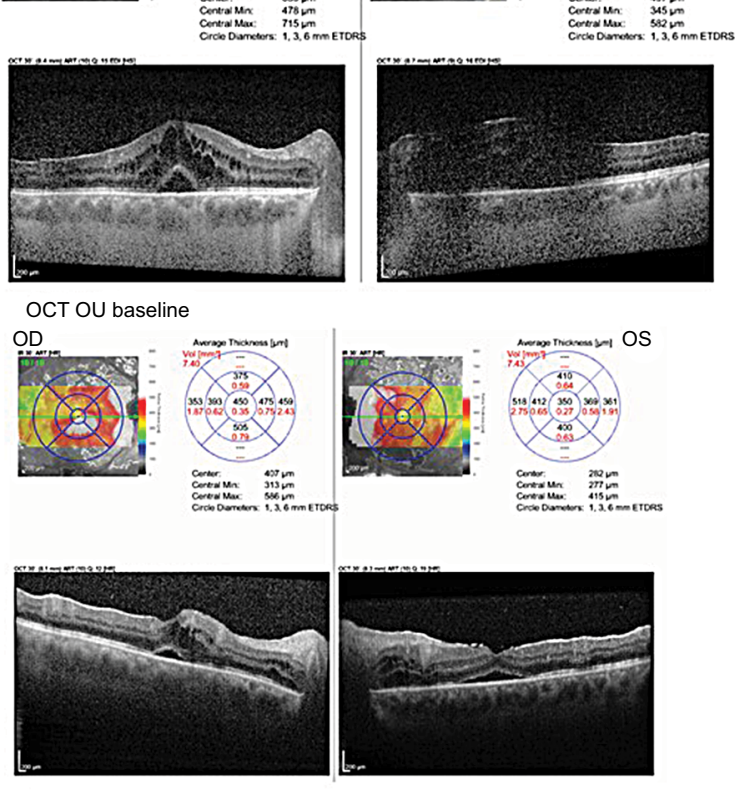

OCT OU final

Figure 3 Case 3 HVF (baseline) and macular OCT at baseline, relapse, and final visit. Abbreviations: HVF, Humphrey visual field; OCT, optical coherence tomography. 
Table I Demographics and clinical parameters

\begin{tabular}{|c|c|c|c|c|c|c|c|c|}
\hline Patient & $\begin{array}{l}\text { Age } \\
\text { (years) }\end{array}$ & Gender & $\begin{array}{l}\text { HLA } \\
\text { status }\end{array}$ & DEX dates & $\begin{array}{l}T_{\max } \text { on } \\
\text { DEX }\end{array}$ & $\begin{array}{l}\text { Number } \\
\text { of DEX }\end{array}$ & Last FU & $\begin{array}{l}\text { Study } \\
\text { parameters }\end{array}$ \\
\hline Patient I & 55 & Male & $\begin{array}{l}\text { HLA A } \\
29\end{array}$ & $\begin{array}{l}\text { First - October } 2013 \\
\text { (OD), September } \\
2013 \text { (OS), second } \\
\text { - April 2014 (OU)', } \\
\text { third - October } 2014 \\
\text { (OU)' }\end{array}$ & 19,19 & $\begin{array}{l}3 \text { OD, } 3 \\
\text { OS }\end{array}$ & August 2015 & $\begin{array}{l}\text { BCVA (OD, } \\
\text { OS) } \\
\text { IOP (OD, } \\
\text { OS) } \\
\text { Inflammatory } \\
\text { status ( } \pm \text { ) } \\
\text { CMT (OD, } \\
\text { OS) } \\
\text { HVF (MD } \\
\text { OD, OS) } \\
\text { NEI VFQ } \\
\text { score }\end{array}$ \\
\hline Patient 2 & 47 & Male & $\begin{array}{l}\text { HLA A } \\
29\end{array}$ & $\begin{array}{l}\text { First - March } 2014 \\
\text { (OU)', second - July } \\
2014 \text { (OU)', third } \\
\text { - November } 2014 \\
\text { (OU)', fourth - } \\
\text { March } 2015 \text { (OU)' }\end{array}$ & 36,22 & $\begin{array}{l}4 \text { OD, } 4 \\
\text { OS }\end{array}$ & . & $\begin{array}{l}\text { BCVA (OD, } \\
\text { OS) } \\
\text { IOP (OD, } \\
\text { OS) } \\
\text { Inflammatory } \\
\text { status ( } \pm \text { ) } \\
\text { CMT (OD, } \\
\text { OS) } \\
\text { HVF (MD } \\
\text { OD, OS) } \\
\text { NEI VFQ } \\
\text { score }\end{array}$ \\
\hline Patient 3 & 46 & Male & $\begin{array}{l}\text { HLA A } \\
29\end{array}$ & $\begin{array}{l}\text { October } 2014 \text { (OD), } \\
\text { September } 2014 \text { (OS) }\end{array}$ & 45,54 & $\begin{array}{l}\text { I OD, I } \\
\text { OS }\end{array}$ & August 2015 & $\begin{array}{l}\text { BCVA (OD, } \\
\text { OS) }\end{array}$ \\
\hline
\end{tabular}

Notes: a 0-2 visual field preferred given central field involvement; 'timolol OU started, (OU)' DEX both eyes approximately 2 weeks apart.

Abbreviations: ADA, adalimumab; BCVA, best-corrected visual acuity; CMT, central macular thickness; MD, mean defect; CSA, cyclosporine; DEX, dexamethasone implant; FU, follow-up; HVF, Humphrey visual field test; MM, mycophenolate mofetil; NA, not applicable; na, not available; NEI VFQ, National Eye Institute Visual Function Questionnaire-25; Oc HTN, ocular hypertension; PO Pred, oral prednisone; PSC, posterior subcapsular cataract. 


\begin{tabular}{|c|c|c|c|c|c|c|c|c|}
\hline Baseline & $\begin{array}{l}\text { Post } \\
\text { implant I }\end{array}$ & $\begin{array}{l}\text { Post } \\
\text { implant } 2\end{array}$ & $\begin{array}{l}\text { Post } \\
\text { implant } 3\end{array}$ & $\begin{array}{l}\text { Post } \\
\text { implant } 4\end{array}$ & $\begin{array}{l}\text { Last } \\
\text { FU }\end{array}$ & $\begin{array}{l}\text { TM before } \\
\text { DEX }\end{array}$ & $\begin{array}{l}\text { TM last } \\
\text { FU }\end{array}$ & $\begin{array}{l}\text { DEX } \\
\text { complications }\end{array}$ \\
\hline $\begin{array}{l}20 / 25 \\
20 / 50\end{array}$ & $\begin{array}{l}20 / 20 \\
20 / 40\end{array}$ & $\begin{array}{l}20 / 30 \\
20 / 70+2\end{array}$ & $\begin{array}{l}20 / 20 \\
20 / 30\end{array}$ & $\mathrm{NA}+$ & $\begin{array}{l}20 / 30 \\
20 / 60\end{array}$ & $\begin{array}{l}\text { CSA, PO } \\
\text { Pred }\end{array}$ & $\begin{array}{l}\text { MM, } \\
\text { CSA }\end{array}$ & PSC OD \\
\hline II, II & 19,19 & 15,15 & 13,15 & $\mathrm{NA}+$ & 12,13 & & & \\
\hline Vitritis & Vitritis I+ & Vitritis I+ & Vitritis I+ & $\mathrm{NA}+$ & Quiet & & & \\
\hline $2+O U$ & OU & $\begin{array}{l}\text { OD, haze } \\
\text { OS }\end{array}$ & OU & & OU & & & \\
\hline 359,269 & 273,262 & na & 289,279 & $\mathrm{NA}+$ & 237, 227 & & & \\
\hline-13.5 & na & na & na & $\mathrm{NA}+$ & -9.35 , & & & \\
\hline$-14.5^{a}$ & & & & & -8.47 & & & \\
\hline 55.19 & 64.28 & & & $\mathrm{NA}+$ & 75.12 & & & \\
\hline $\begin{array}{l}20 / 25 \\
20 / 20\end{array}$ & $\begin{array}{l}20 / 25 \\
20 / 25\end{array}$ & $\begin{array}{l}20 / 25 \\
20 / 25\end{array}$ & $\begin{array}{l}20 / 25 \\
20 / 25\end{array}$ & $\begin{array}{l}20 / 25 \\
20 / 20\end{array}$ & $\begin{array}{l}20 / 30 \\
20 / 25\end{array}$ & None & MM & $\begin{array}{l}\text { Oc HTN OU } \\
\text { PSC OU }\end{array}$ \\
\hline 14,18 & 16,18 & $22,24^{b}$ & 22,24 & 36,22 & 19,17 & & & \\
\hline Vitritis & Vitritis I+ & Vitritis I+ & Vitritis I+ & Vitritis I+ & Quiet & & & \\
\hline $2+O U$ & OU & OU & & OU & OU & & & \\
\hline 351,332 & 305,299 & na & 298,296 & 302,305 & 327,314 & & & \\
\hline$-5.1,-2.5$ & na & na & na & $-6.5,-4.8$ & $\begin{array}{l}-3.4 I \\
-1.85\end{array}$ & & & \\
\hline 75.34 & 93.56 & & & & 85.41 & & & \\
\hline 20/80, & 20/40, & $\mathrm{NA}+$ & $\mathrm{NA}+$ & $\mathrm{NA}+$ & $20 / 30$, & PO Pred, & MM, & None \\
\hline $20 / 80$ & $20 / 20$ & & & & $20 / 40$ & $\begin{array}{l}\text { subtenon } \\
\text { kenalog OU, } \\
\text { dorzolamide } \\
+ \text { timolol } \\
\text { OU }\end{array}$ & & \\
\hline 32,29 & 45,54 & $\mathrm{NA}+$ & $\mathrm{NA}+$ & $\mathrm{NA}+$ & 16,16 & & & \\
\hline Vitritis & & $\mathrm{NA}+$ & $\mathrm{NA}+$ & $\mathrm{NA}+$ & $\mathrm{I}+$ cell/ & & & \\
\hline $2+O U$ & & & & & haze & & & \\
\hline 626,491 & 347, 297 & $\mathrm{NA}+$ & $\mathrm{NA}+$ & $\mathrm{NA}+$ & 327,295 & & & \\
\hline$-5.0,-7.0$ & $-2.8,-3.9$ & $\mathrm{NA}+$ & $\mathrm{NA}+$ & $\mathrm{NA}+$ & na & & & \\
\hline 40.37 & 83.6 & & & & 93.23 & & & \\
\hline
\end{tabular}


started on adalimumab therapy. At last FU, he experienced mild improvement in ocular inflammation, normal IOP, and improved CMT (327 OD, 295 OS) (Table 1).

Patient 3's composite NEI VFQ scores are as follows:

- Baseline: 40.7

- Postimplant: 83.6

- Final FU: 93.23

This patient had marked improvement in visual score after Ozurdex implant and even further refinement at last FU.

\section{Discussion}

The objective of this study was to report an extended FU to the previous case series by Walsh et al ${ }^{17}$ of DEX implants in patients with BSCR. DEX is a biodegradable implant containing $0.7 \mathrm{mg}$ preservative-free dexamethasone that releases drug by diffusion in a biphasic fashion. A higher concentration is released during the initial 60 days for rapid control of inflammation, with a decline thereafter and steady-state concentrations for up to 6 months. ${ }^{18}$

We observed immediate improvement in vision-related functioning after placement of the implants in our case series. Two of the three patients showed continued good clinical response to the DEX implant with improved vision, VFQ score, and well-controlled inflammation. These patients required repeat injection approximately every 6 months due to relapse of inflammation. One patient received four, and the other patient three DEX implants before switching to systemic immunotherapy. The reasons for transition of treatment were formation of posterior capsular cataract, progression of disease, and more convenient long-term therapy. The third patient noted improved vision, VFQ score, and decreased inflammation at 1-month postimplantation, but was unable to continue treatment due to increased IOP.

DEX may have a place in the initial management of patients with BSCR as patients are transitioned to IMT, which can take several months for full effect. DEX implantation may be a safer choice than Retisert, ${ }^{21}$ but many patients ultimately require IMT for severe bilateral ocular inflammation. This is a small case series with patients who were severely affected by BSCR at the time of presentation. Owing to the severity of their disease, they were at very high risk of continued decline.

The positive short-term effects of DEX in uveitis have been documented previously both in these patients and elsewhere. ${ }^{17,23}$ A 26-week, sham-controlled, Phase 3 trial demonstrated that four times as many eyes treated with the $700 \mathrm{mg}$ implant had complete resolution of vitreous haze compared to sham treatment at 8 weeks, which was reflected in improvement in BCVA. ${ }^{19}$ Williams et al ${ }^{18}$ reported that more than $50 \%$ of patients with the dexamethasone implant achieved a gain in BCVA of 10-15 letters compared to observation alone. Another study of intermediate and posterior segment noninfectious uveitis published in 2011 reported the implant to be well tolerated and produced meaningful improvements in intraocular inflammation and visual acuity that persisted through 6 months. ${ }^{20}$

In our study, both patients who elected repeat implants required them approximately every 6 months. The third patient showed adequate control of inflammation, but began IMT at 6 months due to inability to control IOP. The exact duration of activity of DEX is somewhat unclear, but Lowder et $\mathrm{al}^{19}$ report improvements in visual functioning as early as 8 weeks that were maintained over 26 weeks. They also found a longer median survival time for second implant, reporting it to be 13 months. ${ }^{19}$ These results require further evaluation with a larger population size, but in our case series it appeared that the drug remains effective for 6 months.

DEX is also known to be beneficial in the treatment of persistent CME. It is especially effective in cases of uveitis, in which it provides both a more rapid resolution of $\mathrm{CME}$ and a longer effect duration than it does in other etiologies of CME ${ }^{19}$ In a retrospective study of eight eyes with uveitic CME, intravitreal DEX injections resulted in resolution of macular edema and visual acuity improvement. Some eyes required repeat injections, but most eyes achieved long-term resolution. No significant complications were noted. ${ }^{22}$ One of our patients had severe SRF and CME on OCT before implant, which initially resolved with DEX implant. It was then necessary to switch to systemic IMT in this patient due to increased IOP with the DEX, and the SRF and CME returned after 6 months on this treatment. The other two patients saw resolution of macular edema that did not recur throughout the time they received DEX treatment.

Two of the patients in this report developed early posterior subcapsular cataracts during their treatment. In a Phase 3 trial of DEX, no statistically significant differences in the rate of cataract progression or surgery were observed between the treated and sham groups over 26 weeks. ${ }^{19}$ It may be that the high rate of cataract formation seen in this study was a result of repeated injections, as the patients received three and four implants, respectively, in the affected eyes. It also may be that these patients were susceptible to develop cataract regardless of treatment. A longer FU period is needed to assess the long-term rates of cataract progression and surgery. 
In our study, one of the three patients developed persistent IOP $>21 \mathrm{mmHg}$, requiring glaucoma medication, while the other patient has had worsening IOP control of his uveitic glaucoma. A case series by Lowder et $\mathrm{al}^{19}$ found the percentage of patients with IOP of $25 \mathrm{mmHg}$ or more peaked at $7.1 \%$ for the $0.7 \mathrm{mg}$ DEX implant, $8.7 \%$ for the $0.35 \mathrm{mg}$ DEX implant, and $4.2 \%$ for the sham. In a comparative study of Retisert and DEX, none of the eyes in the DEX group needed additional glaucoma medications, glaucoma surgery, or laser compared to a total of $44 \%$ of eyes in the Retisert group. ${ }^{21}$ Another 6-month study also indicated that this implant confers much less of a risk of Oc HTN than other forms of intraocular steroid therapy. ${ }^{20}$ This patient's IOP returned to normal after discontinuing DEX treatment and he was able to discontinue hypotensive medication within a few months after discontinuing treatment without any permanent sequelae of glaucoma. This study is a small case series, and a larger cohort will be required to study the long-term effects of DEX on IOP and progression to glaucoma.

The primary limitations of this study are that it is a small case series, is retrospective in nature, and does not have a lengthy FU period. Because the NEI VFQ-25 responses are based on vision in both eyes, results are highly influenced by vision in the better-seeing eye.

\section{Conclusion}

In conclusion, this study shows that the DEX implant is effective in acutely controlling inflammation and improving visual function in BSCR. Thus, it has the potential to play a role in the treatment of BSCR as an adjunct to systemic immunotherapy or to control inflammation before immunotherapy can be initiated. However, it may not be seen as a potential permanent treatment or monotherapy due to the need for reimplantation every 6 months, disease progression, and development of adverse effects such as cataract progression and increased IOP. Larger and prospective trials are needed to better evaluate the long-term efficacy and safety data in patients who receive multiple injections.

\section{Disclosure}

The authors report no conflicts of interest in this work.

\section{References}

1. Levinson RD, Brezin A, Rothova A, Accorinti M, Holland GN. Research criteria for the diagnosis of birdshot chorioretinopathy: results of an international consensus conference. Am J Ophthalmol. 2006;141(1):185-187.
2. Shah KH, Levinson RD, Yu F, et al. Birdshot chorioretinopathy. Surv Ophthalmol. 2005;50(6):519-541.

3. Ryan SJ, Maumenee AE. Birdshot retinochoroidopathy. Am J Ophthalmol. 1980;89(1):31-45.

4. Kaplan HJ, Aaberg TM. Birdshot retinochoroidopathy. Am J Ophthalmol. 1980;90(6):773-782.

5. Priem HA, Oosterhuis JA. Birdshot chorioretinopathy: clinical characteristics and evolution. Br J Ophthalmol. 1988;72(9):646-659.

6. Nussenblatt RB, Mittal KK, Ryan S, Green WR, Maumenee AE. Birdshot retinochoroidopathy associated with HLA-A29 antigen and immune responsiveness to retinal S-antigen. Am J Ophthalmol. 1982;94(2):147-158.

7. Jobin D, Thillaye B, de Kozak Y, Sainte-Laudy J, Faure JP, Le Hoang P. Severe retinochoroidopathy: variations of humoral and cellular immunity to S-antigen in a longitudinal study. Curr Eye Res. 1990;(9 Suppl):91-96.

8. Boisgerault F, Khalil I, Tieng V, et al. Definition of the HLA-A29 peptide ligand motif allows prediction of potential T-cell epitopes from the retinal soluble antigen, a candidate autoantigen in birdshot retinopathy. Proc Natl Acad Sci U S A. 1996;93(8):3466-3470.

9. Rothova A, Berendschot TT, Probst K, van Kooij B, Baarsma GS. Birdshot chorioretinopathy: long-term manifestations and visual prognosis. Ophthalmology. 2004;111(5):954-959.

10. Sobrin L, Lam BL, Liu M, Feuer WJ, Davis JL. Electroretinographic monitoring in birdshot chorioretinopathy. Am J Ophthalmol. 2005;140(1):52.e1-5252.

11. Thorne JE, Jabs DA, Peters GB, Hair D, Dunn JP, Kempen JH. Birdshot retinochoroidopathy: ocular complications and visual impairment. $A m$ J Ophthalmol. 2005;140(1):45.e1-4545.

12. Oh KT, Christmas NJ, Folk JC. Birdshot retinochoroiditis: long term follow-up of a chronically progressive disease. Am J Ophthalmol. 2002;133(5):622-629.

13. Vitale AT, RodriguezA, Foster CS. Low-dose cyclosporin A therapy in treating chronic, noninfectious uveitis. Ophthalmology. 1996;103(3):365-374.

14. Bajwa A, Aziz K, Foster CS. Safety and efficacy of fluocinolone acetonide intravitreal implant $(0.59 \mathrm{mg})$ in birdshot retinochoroidopathy. Retina. 2014;34(11):2259-2268.

15. Burkholder BM, Wang J, Dunn JP, Nguyen QD, Thorne JE. Postoperative outcomes after fluocinolone acetonide implant surgery in patients with birdshot chorioretinitis and other types of posterior and panuveitis. Retina. 2013;33(8):1684-1693.

16. Rush RB, Goldstein DA, Callanan DG, Meghpara B, Feuer WJ, Davis JL. Outcomes of birdshot chorioretinopathy treated with an intravitreal sustained-release fluocinolone acetonide-containing device. Am JOphthalmol. 2011;151(4):630-636.

17. Walsh J, Reddy AK. Intravitreal dexamethasone implantation for birdshot chorioretinopathy. Retin Cases Brief Rep. 2017;11(1):51-55.

18. Williams GA, Haller JA, Kuppermann BD, et al. Dexamethasone posterior-segment drug delivery system in the treatment of macular edema resulting from uveitis or Irvine-Gass syndrome. Am J Ophthalmol. 2009;147(6):e1041-1042:1048-1054.

19. Lowder C, Belfort R, Lightman S, et al. Dexamethasone intravitreal implant for noninfectious intermediate or posterior uveitis. Arch Ophthalmol. 2011;129(5):545-553.

20. Saraiya NV, Goldstein DA. Dexamethasone for ocular inflammation. Expert Opin Pharmacother. 2011;12(7):1127-1131.

21. Arcinue CA, Cerón OM, Foster CS. A comparison between the fluocinolone acetonide (Retisert) and dexamethasone (Ozurdex) intravitreal implants in uveitis. J Ocul Pharmacol Ther. 2013;29(5):501-507.

22. Habot-Wilner Z, Sorkin N, Goldenberg D, Loewenstein A, Goldstein M. Long-term outcome of an intravitreal dexamethasone implant for the treatment of noninfectious uveitic macular edema. Ophthalmologica. 2014;232(2):77-82.

23. Moisseiev E, Moshiri A. Ozurdex for the Treatment of a Patient with Birdshot Chorioretinopathy. Case Rep Ophthalmol. 2015;6(3):289-292. 
International Medical Case Reports Journal

Dovepress

Publish your work in this journal

The International Medical Case Reports Journal is an international, peer-reviewed open-access journal publishing original case reports from all medical specialties. Previously unpublished medical posters are also accepted relating to any area of clinical or preclinical science. Submissions should not normally exceed 2,000 words or

4 published pages including figures, diagrams and references. The manuscript management system is completely online and includes a very quick and fair peer-review system, which is all easy to use. Visit http://www.dovepress.com/testimonials.php to read real quotes from published authors.

Submit your manuscript here: https://www.dovepress.com/international-medical-case-reports-journal-journal 